\title{
Recommendations of the ESSR Arthritis Subcommittee for the Use of Magnetic Resonance Imaging in Musculoskeletal Rheumatic Diseases
}

Iwona Sudoł-Szopińska, MD, PhD ${ }^{1}$ Anne Grethe Jurik, MD, DMSc ${ }^{2}$ Iris Eshed, $\mathrm{MD}^{3}$ Jans Lennart, $\mathrm{MD}^{4}$ Andrew Grainger, MRCP, FRCR ${ }^{5}$ Mikkel Østergaard, MD, PhD, DMSc ${ }^{6}$ Andrea Klauser, MD $^{7}$ Anne Cotten, MD, $\mathrm{PhD}^{8}$ Marius C. Wick, MD ${ }^{9}$ Mario Maas, MD, PhD ${ }^{10}$ Falk Miese, MD ${ }^{11}$ Niels Egund, MD ${ }^{12}$ Nathalie Boutry, MD ${ }^{13}$ Mitja Rupreht, MD, PhD ${ }^{14}$ Monique Reijnierse, MD ${ }^{15}$ Edwin H. G. Oei, MD, PhD ${ }^{16}$ Reinhard Meier, MD ${ }^{17}$ Phil O'Connor, MD ${ }^{18}$ Antoine Feydy, MD, PhD ${ }^{19}$ Vasco Mascarenhas, MD ${ }^{20}$ Athena Plagou, MD ${ }^{21}$ Paolo Simoni, MD ${ }^{22}$ Hannes Platzgummer, MD ${ }^{23}$ Winston J. Rennie, MBBS ${ }^{24}$ Adam Mester, MD ${ }^{25}$ James Teh, MD ${ }^{26}$ Philip Robinson, MB ChB, MRCP, FRCR ${ }^{27}$ Giuseppe Guglielmi, MD ${ }^{28}$ Gunnar Åström, MD ${ }^{29}$ Claudia Schueller-Weiderkamm, MD ${ }^{30}$

${ }^{1}$ Department of Radiology, National Institute of Geriatrics, Rheumatology and Rehabilitation, Warsaw, Poland, and Imaging Diagnostic Department, Warsaw Medical University, Poland

${ }^{2}$ Division of Radiology, Aarhus University Hospital, Aarhus, Denmark

${ }^{3}$ Department of Diagnostic Imaging, The Sheba Medical Center, Tel Aviv University, Tel Aviv, Israel

${ }^{4}$ Department of Radiology, Ghent University Hospital, Ghent, Belgium

${ }^{5}$ Department of MSK Radiology, Leeds Teaching Hospitals, Chapel Allerton Orthopaedic Centre, Leeds, United Kingdom

${ }^{6}$ Copenhagen Center for Arthritis Research, Center for Rheumatology and Spine Diseases, Rigshospitalet, Glostrup and University of Copenhagen, Glostrup, Denmark

${ }^{7}$ Department of Radiology, Medical University Innsbruck, Section Rheumatology and Sports Imaging, Innsbruck, Austria

${ }^{8}$ Department of Musculoskeletal Radiology, University Hospital of Lille, Lille, France

${ }^{9}$ Department of Radiology, Karolinska University Hospital, Stockholm, Sweden

${ }^{10}$ Division of Musculoskeletal Radiology, Department of Radiology, University of Amsterdam, Academic Medical Center, Amsterdam, The Netherlands

${ }^{11}$ Department of Diagnostic and Interventional Radiology, University Düsseldorf and Practice for Radiology, Nuklear Medicine and Radiotherapy, Bottop, German

${ }^{12}$ Department of Radiology, Aarhus University Hospital Aarhus C, Aarhus, Denmark

${ }^{13}$ Service de Radiopédiatrie, Hôpital Jeanne de Flandre, CHRU de Lille, Lille, France

${ }^{14}$ Department of Radiology, UMC Maribor, Maribor, Slovenia

${ }^{15}$ Department of Radiology, Leiden University Medical Center, Leiden, The Netherlands
${ }^{16}$ Department of Radiology, Erasmus MC Rotterdam, Rotterdam, The Netherlands

${ }^{17}$ Department of Diagnostic and Interventional Radiology, University Hospital Ulm, Ulm, Germany

${ }^{18} \mathrm{NIHR}$ Leeds Musculoskeletal Biomedical Imaging Unit, Leeds Teaching Hospitals, Leeds, United Kingdom

${ }^{19}$ Department of Radiology B, Cochin Hospital, Paris University of Descartes, Paris Cedex, France

${ }^{20}$ Department of Diagnostic Imaging, Hospital da Luz, Luz-Saude, Lisbon, Portugal

${ }^{21}$ Ultrasound Unit, Private Radiological Institution, Athens, Greece

${ }^{22}$ Department of Radiology, University of Bruxelles, Reine Fabiola Children's University Hospital of Bruxelles, Brussels, Belgium

${ }^{23}$ Department of Biomedical Imaging und Image-guided Therapy, Medical University of Vienna, Vienna, Austria

${ }^{24}$ Department of Radiology, Hospitals of Leicester, Leicester Royal Infirmary, Leicester, United Kingdom

${ }^{25}$ Department of Radiology, National Institute of Rheumatology and Physiotherapy, Budapest, Hungary

${ }^{26}$ Department of Radiology, Oxford University Hospitals NHS Trust, Nuffield Orthopaedic Centre, Oxford, United Kingdom

${ }^{27}$ Department of MSK Radiology, Leeds Teaching Hospitals, Chapel Allerton Orthopaedic Centre, Leeds, United Kingdom

${ }^{28}$ Department of Radiology, Scientific Institute Hospital "Casa Sollievo della Sofferenza," San Giovanni Rotondo, Italy

${ }^{29}$ Department of Radiology, Akademiska Sjukhuset, University Hospital, Uppsala, Sweden

${ }^{30}$ Division of Neuroradiology and Musculoskeletal Radiology, Department of Biomedical Imaging and Image-guided Therapy, University of Vienna, Vienna, Austria
Address for correspondence Iwona Sudoł-Szopińska, MD, PhD, Department of Radiology, Institute of Rheumatology, Warsaw, Poland, and Imaging Diagnostic Department, Warsaw Medical University, Poland (e-mail: sudolszopinska@gmail.com).
Issue Theme Update on Advances in Musculoskeletal Magnetic Resonance Imaging; Guest Editor, Patrick Omoumi, $\mathrm{MD}, \mathrm{MSc}, \mathrm{PhD}$
Copyright @ 2015 by Thieme Medical Publishers, Inc., 333 Seventh Avenue, New York, NY 10001, USA. Tel: +1(212) 584-4662.
DOI http://dx.doi.org/ 10.1055/s-0035-1564696. ISSN 1089-7860. 


\begin{abstract}
This article presents the recommendations of the European Society of Musculoskeletal Radiology Arthritis Subcommittee regarding the standards of the use of MRI in the diagnosis of musculoskeletal rheumatic diseases. The recommendations discuss (1) the

Keywords

- arthritis

- sacroiliitis

- spondyloarthritis

- magnetic resonance imaging

- diagnosis role of MRI in current classification criteria of musculoskeletal rheumatic diseases (including early diagnosis of inflammation, disease follow-up, and identification of disease complications); (2) the impact of MRI on the diagnosis of axial and peripheral spondyloarthritis, rheumatoid arthritis, and juvenile spondyloarthritis; (3) MRI protocols for the axial and peripheral joints; (4) MRI interpretation and reporting for axial and peripheral joints; and finally, (5) methods for assessing MR images including quantitative, semiquantitative, and dynamic contrast-enhanced MRI studies.
\end{abstract}

This article presents the recommendations of the European Society of Musculoskeletal Radiology (ESSR) Arthritis Subcommittee regarding the standards of the use of MRI in radiology and rheumatology to standardize the diagnostic work-up of patients with suspected or diagnosed rheumatic diseases of the musculoskeletal system.

The article was prepared on the basis of clinical expertise, current literature, as well as the guidelines of the ESSR, the Assessment of SpondyloArthritis International Society (ASAS), and the European League Against Rheumatism (EULAR). ${ }^{1-8}$

These recommendations discuss the following topics:

1. The role of MRI in current classification criteria of musculoskeletal rheumatic diseases

2. The impact of MRI on the diagnosis of musculoskeletal rheumatic diseases

3. MRI protocols

4. MRI interpretation and reporting

5. Methods for assessing MR images

\section{The Role of MRI in Current Classification Criteria of Rheumatic Diseases}

MRI is currently considered the best noninvasive observerindependent imaging modality to evaluate the inflammation of joints, tendons, entheses, and bone marrow.

These are the main indications for MRI in patients with musculoskeletal rheumatic diseases:

- Early diagnosis of inflammation

- Confirmation of the presence of clinically active changes and postinflammatory structural lesions

- Disease follow-up including monitoring of therapy response

- Identification of disease complications

In particular, MRI facilitates the following assessments:

- Peripheral joints for active inflammation in the form of effusion, synovitis, bone marrow edema (BME), as well as the subsequent structural lesions, such as articular surface damage and cortical bone erosions

- Active inflammatory lesions and structural changes in the sacroiliac joints
- Inflammatory and postinflammatory lesions of the vertebral joints (i.e., assessment of the inflammatory activity, aseptic spondylodiscitis, atlantoaxial/atlanto-occipital structural lesions

- Tenosynovitis and enthesitis

It also confirms the clinical diagnosis based on imaging characteristics and/or location of lesions, and it provides qualitative, semiquantitative, and quantitative measurements of active inflammation and chronic joint damage.

Disadvantages of MRI include long examination times, limited availability, limited field of view (normally a single joint/group of joints, like a hand, is examined), relatively high cost, need for contrast medium to increase specificity, and contraindications in certain patients.

\section{Impact of MRI on the Diagnosis of Musculoskeletal Rheumatic Diseases}

\section{Axial Spondyloarthritis}

MRI plays an important role in the diagnosis of axial spondyloarthritis (SpA) by detecting sacroiliitis (ASAS imaging arm) more sensitively and also with a better reproducibility compared with conventional radiography ${ }^{8}$ (-Table 1). Spinal inflammatory lesions suggestive of axial $\mathrm{SpA}$ are rarely found in the absence of sacroiliitis on MRI (or radiography). ${ }^{9}$

In patients with clinically suspected axial SpA, MRI is most commonly performed for the following reasons ${ }^{5}$ :

- To visualize active inflammatory lesions in the sacroiliac joints and the spine, particularly in young patients or patients with a short history of disease, or where clinical findings and conventional radiography fail to confirm the disease definitively

- To show structural lesions early in the disease course

- To monitor disease activity and assess response to therapy

The role of MRI needs to be determined to:

- Monitor structural changes of the sacroiliac joints and the spine

- Predict development of new syndesmophytes from socalled vertebral corner inflammatory lesions 
Table 1 ASAS 2010 criteria for classification of axial spondyloarthritis $2,3,8$

\begin{tabular}{|l|l|l|}
\hline Back pain $\geq 3$ mo and age at onset $<45$ y \\
\hline Sacroiliitis on imaging $^{\mathrm{a}}$ and one or more SpA features & or & HLA-B27 positive and two or more other SpA features \\
\hline
\end{tabular}

Abbreviations: ASAS, Assessment of SpondyloArthritis Society; HLA-B237, human leukocyte antigen B27; SpA, spondyloarthritis.

${ }^{a}$ Active inflammation on MRI highly suggestive for sacroiliitis associated with SpA or definite radiographic sacroiliitis according to the modified New York criteria (1984).

bSpA features: inflammatory back pain (at least four of the following symptoms must occur: pain onset before the age of 40, insidious onset, improvement with exercise, no improvement with rest; pain at night with improvement upon getting up, peripheral arthritis, enthesitis, uveitis, dactylitis, psoriasis, diagnosed Crohn disease or ulcerative colitis, good response to nonsteroidal anti-inflammatory drugs, familial history of SpA, HLA-B27 positivity, elevated C-reactive protein.

\section{Peripheral Spondyloarthritis}

Patients presenting with clinical symptoms of peripheral arthritis, tenosynovitis, bursitis, enthesitis, or swelling of the finger(s) (-Table 2) are referred for MRI when conventional radiographs and/or ultrasound findings are inconclusive or normal.

MRI is performed to ${ }^{5}$ :

- Diagnose active inflammatory lesions

- Monitor disease activity

- Diagnose complications, such as cartilage damage, tendons tears, and avascular necrosis

\section{Rheumatoid Arthritis}

Imaging is not a mandatory part of the current American College of Rheumatology ACR/EULAR classification criteria for rheumatoid arthritis (RA), ${ }^{6,7}$ but importantly MRI (and ultrasonography [US]) can be used to count involved joints in case of diagnostic uncertainty. In the ACR/EULAR 2010 criteria for RA, ${ }^{6}$ classification as RA is based on the presence of definite clinical synovitis (swelling at clinical examination) in one or more joints, absence of an alternative diagnosis that better explains the synovitis, and achievement of a total score $\geq 6$ of a possible 10 from the individual scores in four domains (including imaging findings). In the joint involvement domain, which can provide up to five of the six required points for an RA diagnosis, MRI and US can be used to determine the joint involvement. ${ }^{6,10,11}$ However, the clinical impact of MRI in the early diagnosis of RA needs to be determined. $^{12,13}$

Apart from assessment of joint involvement, MRI allows detection of inflammatory changes in tendon sheaths and bursae, as well as bone marrow involvement.
In addition, the EULAR recommendations for the use of imaging in the clinical management of RA recommend MRI for $^{6,14,15}$ :

- Assessing prognosis (synovitis and BME in particular are risk factors for the progression to structural changes)

- Predicting and assessing treatment response

- Monitoring disease activity and progression

- Assessing cervical spine involvement

- Assessing inflammatory lesions that are not detected on clinical examination

\section{Juvenile Idiopathic Arthritis and Juvenile Spondyloarthritis}

The evaluation of articular disorders in children differs from that in adults in several respects and remains challenging. ${ }^{16}$

MRI is more sensitive than physical examination, conventional radiography, or US for the evaluation of inflammatory as well as destructive changes in juvenile idiopathic arthritis (JIA) and juvenile spondyloarthritis (JSpA). ${ }^{17,18}$ Optimized MRI protocols permit application of the procedure without sedation or anesthesia in pediatric patients as young as 5 years of age. ${ }^{19}$ MRI features in JIA knee joint ${ }^{20,21}$ and the wrist and metacarpophalangeal joints ${ }^{16}$ can be scored using several systems; the temporomandibular joint (TMJ) is currently a focus of international interest. ${ }^{22}$

Clinical applications of MRI in JIA and JSpA include the following ${ }^{23-27}$ :

- Initial confirmation of clinical diagnosis and differential diagnoses

- Assessment of disease activity in joints that are difficult to evaluate clinically (and by US, such as the hip, TMJ, subtalar joint, spine, and sacroiliac joints

Table 2 ASAS classification criteria for peripheral spondyloarthritis 3,4

\begin{tabular}{|l|l|}
\hline Peripheral arthritis, enthesitis, or dactylitis plus \\
\hline One or more SpA features: & Two or more other SpA features: \\
Psoriasis & Arthritis \\
Crohn disease or ulcerative colitis & Enthesitis \\
Preceding infection & Dactylitis/sausage-like fingers and toes \\
HLA-B27 positivity & Inflammatory back pain \\
Uveitis & Familial history of SpA \\
Definitive sacroiliitis on conventional radiographs or MRI & \\
\hline
\end{tabular}

Abbreviations: ASAS, Assessment of SpondyloArthritis Society; HLA-B237, human leukocyte antigen B27; SpA, spondyloarthritis. 


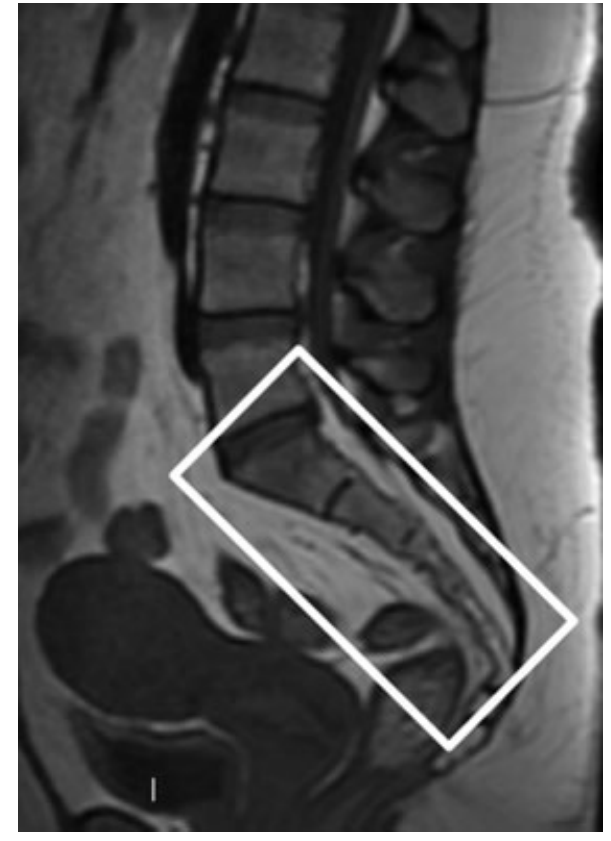

Fig. 1 MR sagittal localizer image shows imaging planes of coronal oblique slices of sacroiliac joints relative to the tangent of the posterior surface of the $\mathrm{S} 2$ vertebral body.

\section{- Assessment of subclinical synovitis}

- Assessment of structural lesions, such as cartilage damage and erosions in peripheral joints, and structural lesions in the spine and sacroiliac joints

- Therapy monitoring

- Recognition of complications (e.g., cervical spine subluxation with potential cord compression)

\section{MRI Protocols}

MR examination of specific anatomical regions is performed using dedicated spinal, hand, ankle-foot, or body phasedarray coils. If indicated, whole-body MRI scans may also be acquired when looking for active inflammation.

In case of the use of a low magnetic field MR scanner dedicated for the examination of small joints (e.g., 0.2- to 1-T field strengths), its limited field of view $\sim 12 \mathrm{~cm}$, and implications for fat-suppression (FS) techniques need consideration.

In RA, scanning of both hands would be optimal but is often not feasible with adequate image quality. In clinical practice, in some units the most symptomatic hand or the dominant hand is examined.

The use of intravenous contrast is essential in (early) RA patients and for the detection of (teno)synovitis. ${ }^{28}$

Isotropic three-dimensional (3D) imaging (e.g., 3D spoiled gradient recalled) can also be very useful in the hands and feet. This has particular advantages for follow-up imaging, allowing multiplanar reconstructions to assure the achievement of comparable planes even if patient positioning has not been exactly reproduced.

MRI of the cervical spine is recommended in RA patients with neck pain, neurologic symptoms/signs, and/or radio- graphic signs of instability, including horizontal, rotatory, and vertical subluxation, to evaluate a potential occurrence of active pannus and risk of cord or brainstem compression. ${ }^{29}$

In the early diagnosis of axial SpA, a sacroiliac joints MRI is recommended. For the diagnosis of spinal lesion in axial $\mathrm{SpA}$, a full-spine MRI is recommended. The additional value of spinal MRI to sacroiliac joints MRI has not been clearly shown for establishing the diagnosis of axial SpA. ${ }^{5}$ Howev$\mathrm{er}$, in clinical practice, and especially in case of doubt, spinal MRI may be useful for the positive diagnosis of other diseases (e.g., Modic type 1, Scheuermann disease, diffuse idiopathic skeletal hyperostosis). In SpA patients, the MRI scan range on sagittal slices should be laterally extended to include the paravertebral structures such as facet, costotransversal, and costovertebral joints that are commonly involved in SpA.

MRI protocols can be adjusted taking into consideration the scanner specifications, available coils, and image quality in particular sequences. Short tau inversion recovery (STIR) or turbo inversion recovery magnitude (TIRM), T2-weighted sequences with fat suppression (T2FS) or T2-weighted Dixon, T1-weighted sequences with or without FS and before and/or after contrast injection, and proton-density (PD) FS sequences may be used. ${ }^{1,30-32}$

The size of the field of view and the matrix as well as the slice thickness should be adjusted appropriately. The recommended maximal slice thickness is $3 \mathrm{~mm}$, with an interslice gap of $0.3 \mathrm{~mm}$, depending on the anatomical structure to be assessed. Thinner sections should ideally be performed for small joints.

- Table 3 lists the MRI scanning protocols recommended by the ESSR Arthritis Subcommittee for the assessment of inflammatory changes of the musculoskeletal system in the course of rheumatic diseases.

\section{MRI Interpretation and Reporting}

Subject to the assessment are the T1, T2, and PD-weighted sequences with or without fat saturation or STIR/TIRM sequences, in addition to available postcontrast sequences.

\section{MRI of Sacroiliac Joints}

According to ASAS, the diagnosis of early sacroiliitis by MRI is based on the evaluation of active (-Figs. 1, 2 and 3 ) and structural postinflammatory changes ( - Fig. 4) (-Table 4).

The MRI-based diagnosis of active early sacroiliitis requires the presence and detection of BME. In accordance with the ASAS criteria, other active inflammatory changes, such as synovitis, capsulitis, and enthesitis, are suggestive of sacroiliitis on the condition of concomitant BME in the adjacent areas. ${ }^{8}$ To diagnose these three inflammatory features, contrast- enhanced (CE) MRI is often needed. However, according to the 2015 evidence-based EULAR recommendations, ${ }^{5}$ CE-MRI is not necessary to make a diagnosis of sacroiliitis because BME is the key to the diagnosis and the hallmark of the disease.

MR reports should contain a description of active and structural changes. 
Table 3 MR scanning protocols recommended by the ESSR Arthritis Subcommittee for the assessment of inflammatory changes of the musculoskeletal system in the course of rheumatic diseases

\begin{tabular}{|c|c|}
\hline Examined area & MRI sequences \\
\hline Sacroiliac joints & $\begin{array}{l}\text { Coronal oblique }{ }^{\text {a }} \text { T1-weighted (T1) } \\
\text { Coronal oblique STIR/TIRM or either PD FS, T1 FS or gradient-echo sequence } \\
\text { axial }{ }^{b} \text { PD FS or STIR/TIRM } \\
\text { Obligatory: minimum coronal oblique T1-weighted, coronal oblique STIR/TIRM and a } \\
\text { cartilage sequence and visualization in two perpendicular planes } \\
{ }^{a} \text { Coronal oblique: slice of sacroiliac joints in coronal plane relative to the tangent of the } \\
\text { posterior surface of S2 vertebral body ( }- \text { Fig. 1) } \\
{ }^{5} \text { Axial: a transverse slice of sacroiliac joints perpendicular to the coronal oblique slice }\end{array}$ \\
\hline Spine, SpA & $\begin{array}{l}\text { Sagittal T1-weighted } \\
\text { Sagittal STIR/TIRM } \\
\text { Axial T2FS or FFE (if optimal assessment of osseous edema at the posterior joints is needed) }\end{array}$ \\
\hline Spine, RA & $\begin{array}{l}\text { Sagittal T1-weighted } \\
\text { Sagittal STIR/TIRM } \\
\text { Axial T2 FS or FFE of the atlantoaxial and atlanto-occipital and, when needed, subaxial regions } \\
\text { Coronal T1 in cases with atlantoaxial and/or atlanto-occipital changes suspect for lateral or } \\
\text { rotatory subluxation } \\
\text { Postcontrast sagittal and axial T1 with FS are often needed for clear delineation of active } \\
\text { inflammation. Additional coronal sequence in cases with atlantoaxial and/or atlanto-occipital } \\
\text { changes }\end{array}$ \\
\hline Hand $^{\mathrm{a}}$ & 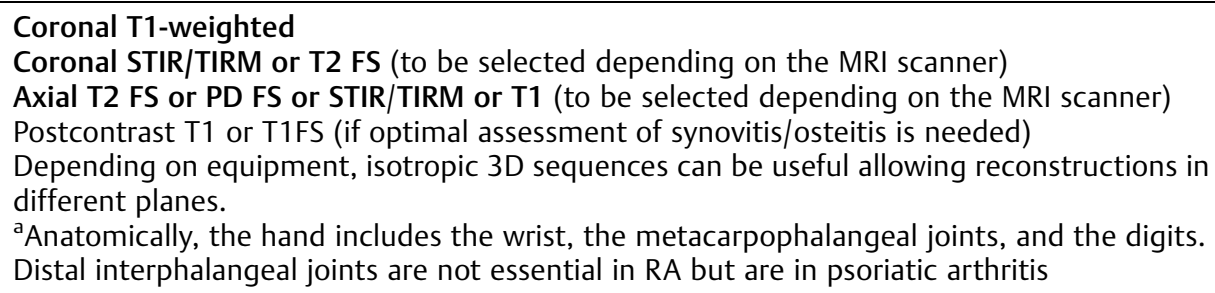 \\
\hline Ankle $^{a}$ & 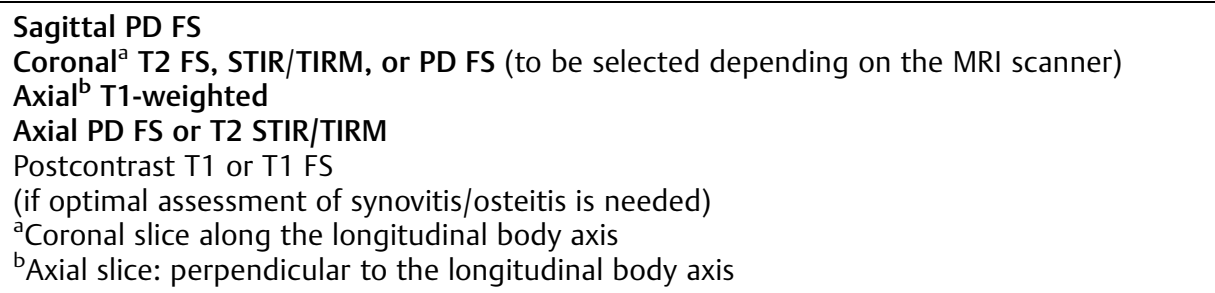 \\
\hline Foot $^{a}$ & $\begin{array}{l}\text { Coronal }{ }^{\mathrm{a}} \text { T2 FS, STIR/TIRM, or PD FS } \\
\text { Axial }^{\mathrm{b}} \text { T1-weighted, STIR/TIRM, T2 FS, or PD FS } \\
\text { Sagittal PD FS } \\
\text { Postcontrast T1 or T1FS } \\
\text { (if optimal assessment of synovitis/osteitis is needed) } \\
\text { aCoronal slice along the longitudinal body axis } \\
{ }^{\mathrm{b}} \text { Axial slice: perpendicular to the longitudinal body axis } \\
\text { Depending on equipment, isotropic 3D sequences can be a possibility allowing reconstruc- } \\
\text { tions in different planes }\end{array}$ \\
\hline Glenohumeral joint & $\begin{array}{l}\text { Axial STIR/TIRM, T2 FS, or PD FS } \\
\text { Coronal oblique T1-weighted } \\
\text { Coronal oblique STIR/TIRM, T2 FS, or PD FS } \\
\text { Sagittal oblique T1- or T2-weighted } \\
\text { Sagittal oblique STIR/TIRM, T2 FS, or PD FS } \\
\text { Obligatory: minimum two PD FS, STIR/TIRM, or T2 FS sequences and minimum one } \\
\text { T1-weighted sequence } \\
\text { Postcontrast T1 or T1 FS (if optimal assessment of synovitis/osteitis is needed) }\end{array}$ \\
\hline $\begin{array}{l}\text { Anterior chest wall joints } \\
\text { (sternoclavicular, } \\
\text { sternocostal, and } \\
\text { manubriosternal joint) }\end{array}$ & $\begin{array}{l}\text { Assessment of inflammatory lesions: } \\
\text { Coronal T1-weighted } \\
\text { Coronal T2 FS or STIR/TIRM } \\
\text { Axial or sagittal T2 FS depending on disease location } \\
\text { Assessment of sternoclavicular articular disks: } \\
\text { Coronal and transverse PDFS } \\
\text { Postcontrast T1 or T1 FS (if optimal assessment of synovitis/osteitis is needed) }\end{array}$ \\
\hline
\end{tabular}


Table 3 (Continued)

\begin{tabular}{|c|c|}
\hline Examined area & MRI sequences \\
\hline Elbow & $\begin{array}{l}\text { Coronal T1-weighted } \\
\text { Axial STIR/TIRM, T2FS, or PD FS } \\
\text { Coronal STIR/TIRM, T2 FS or PD FS } \\
\text { Sagittal T1-weighted } \\
\text { Sagittal PD FS } \\
\text { Obligatory: minimum two PD FS, STIR/TIRM, or T2 FS sequences and minimum one } \\
\text { T1-weighted sequence } \\
\text { Postcontrast T1 or T1FS (if optimal assessment of synovitis/osteitis is needed) }\end{array}$ \\
\hline Hip & $\begin{array}{l}\text { Coronal STIR/TIRM, T2 FS, or PD FS } \\
\text { Coronal T1-weighted } \\
\text { Axial STIR/TIRM, T2FS, or PD FS } \\
\text { Axial T1-weighted } \\
\text { Postcontrast T1 or T1 FS (if optimal assessment of synovitis/osteitis is needed) }\end{array}$ \\
\hline Knee & $\begin{array}{l}\text { Sagittal PD FS } \\
\text { Coronal PD FS } \\
\text { Axial PD FS } \\
\text { Sagittal or coronal T1-weighted } \\
\text { Postcontrast T1 or T1 FS (if optimal assessment of synovitis/osteitis is needed) }\end{array}$ \\
\hline Temporomandibular joints & $\begin{array}{l}\text { Assessment of inflammatory lesions: } \\
\text { Axial or coronal T1-weighted } \\
\text { Axial T2FS or STIR/TIRM } \\
\text { Coronal T2FS or STIR/TIRM } \\
\text { Coronal T2-weighted } \\
\text { Assessment of articular disks and joint mobility: } \\
\text { Sagittal oblique PD (articular disk assessment) } \\
\text { Sagittal oblique PD FS (mouth open and closed) } \\
\text { Postcontrast T1 or T1 FS (if optimal assessment of synovitis/osteitis is needed) }\end{array}$ \\
\hline Whole-body MRI & $\begin{array}{l}\text { Coronal T1-weighted } \\
\text { Coronal T2FS or STIR/TIRM } \\
\text { Sagittal STIR/TIRM and/or T1 of the whole spine }\end{array}$ \\
\hline
\end{tabular}

Abbreviations: 3D, three-dimensional; ESSR, European Society of Skeletal Radiology; FFE, fast-field echo; FS, fat suppressed; PD, proton density; RA, rheumatoid arthritis; SPA, spondyloarthritis; STIR, short tau inversion recovery; TIRM, turbo inversion recovery magnitude.

The present guidelines recommend reports based on visualization of the joints in two perpendicular planes, oblique coronal and oblique axial. The description of findings should contain the site of lesions within the cartilaginous and/or ligamentous sacral/iliac portion of the joint as visualized in the two perpendicular scan directions. If possible, the number and location of these changes for both diagnostic reasons and monitoring of therapy should also be determined.

\section{Active Inflammatory Lesions in MRI Scans}

\section{Bone Marrow Edema}

BME is visible as an area of high signal on T2 FS or STIR/TIRM images and is typically located subchondrally in the cartilaginous parts of the sacroiliac joint (-Figs. 2 and 3). It may be associated with structural changes, such as erosions, fat deposition, or sclerosis.

\section{Capsulitis/Synovitis}

Capsulitis has been described by ASAS as a thickening of the sacroiliac joint capsule and adjacent ligaments, as well as hyperintense signal on T2 FS or STIR/TIRM images and/or hyperintensity on contrast-enhanced T1 FS sequences, representing capsular/ligamentous inflammation, including inflammation in the underlying synovium.

Synovitis presents as a hyperintense signal on contrastenhanced T1FS images, in the synovial part of the sacroiliac joint (ASAS).

However, histologically that there is no capsule or synovium in the proximal two thirds of the joint. ${ }^{33}$ The joint is built as a symphysis with surrounding ligaments. Inflammation adjacent to the joint in this region therefore represents enthesitis.

Synovitis may be present in the distal cartilaginous portion of the joint, and inflammatory changes specifically located to the synovia may possibly be detected on oblique axial postcontrast sequences, but it has never been confirmed in MR studies including oblique axial slices. Although rare, synovitis has been reported in histologic studies. ${ }^{34}$ Also involvement of capsular structures in the distal portion of the joint has not been confirmed in MR studies. 

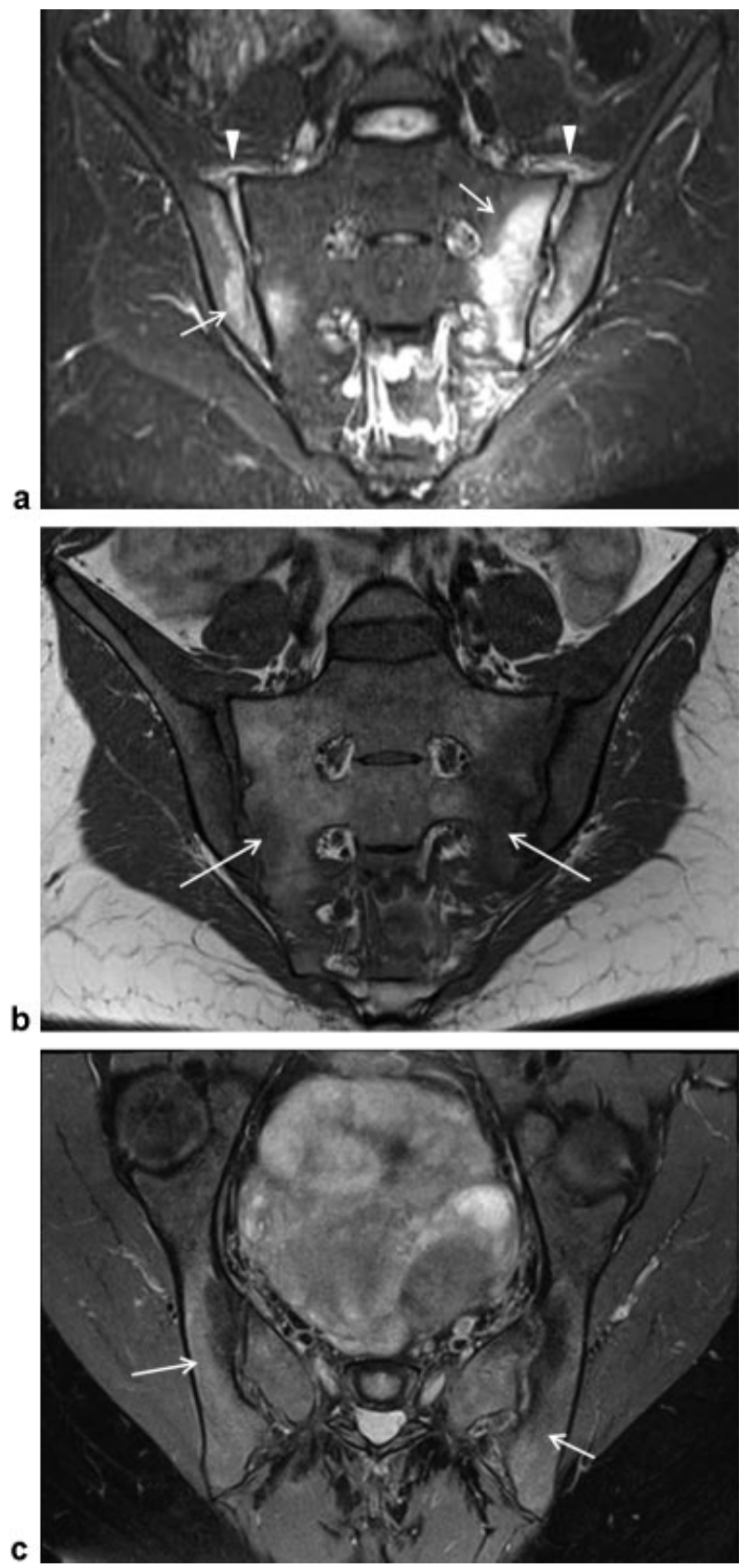

Fig. 2 Active inflammatory lesions of the sacroiliac joints. (a) Paracoronal short tau inversion recovery (b) paracoronal T1-weighted and (c) para-axial proton-density fat-suppressed MR images show bilateral subchondral bone marrow edema (arrows) and high signal in the joints (exudate) as well in the anterosuperior sacroiliac enthesitis (arrowheads) in keeping with spondyloarthritis.

\section{Enthesitis}

Enthesitis is seen as hyperintense signal at sacroiliac ligaments or entheses on STIR/TIRM or T1FS contrast-enhanced images, frequently with BME of the bony part of the entheses (-Fig. 2).

\section{Structural Changes on MRI Scans}

1. Bone erosion: joint facet/subchondral bone abnormalities appearing as few, multiple, localized, or contiguous low
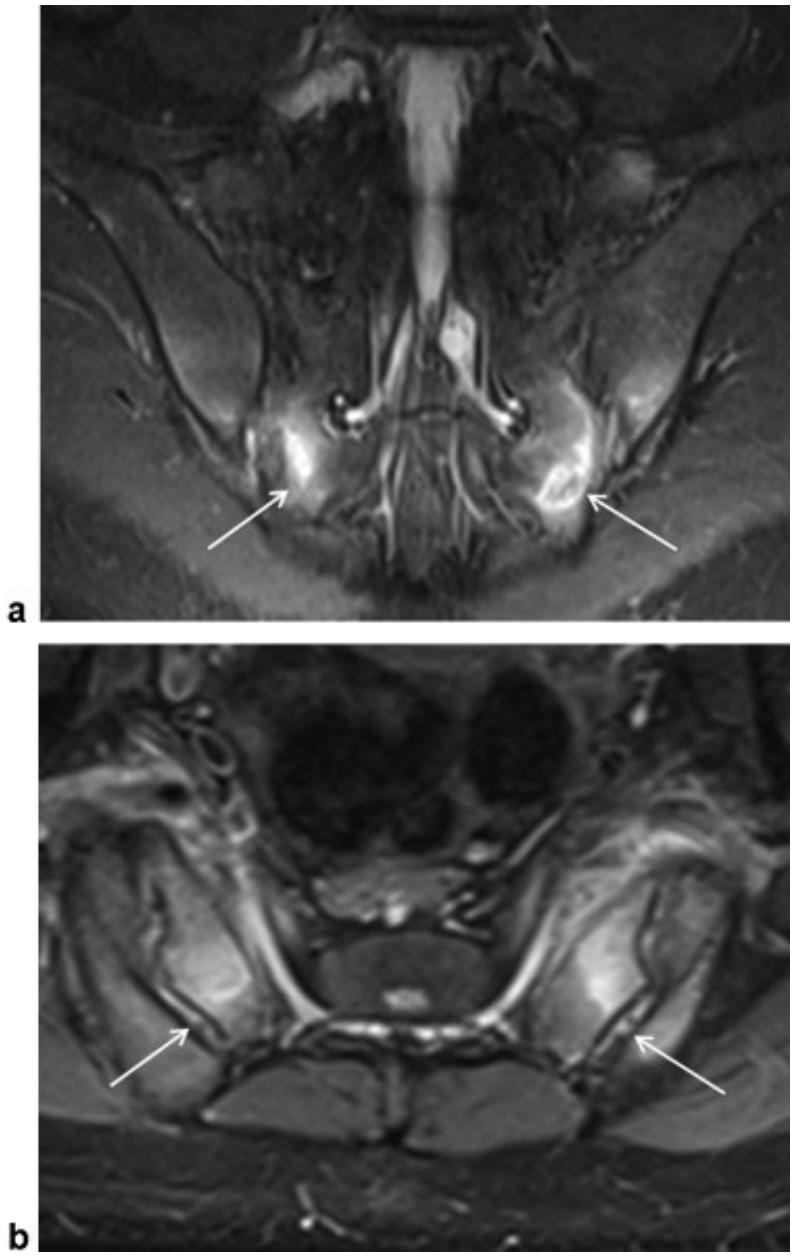

Fig. 3 Sacroiliitis. (a) Coronal oblique and (b) axial short tau inversion recovery images of the sacroiliac joints show bilateral bone marrow edema in both the posterior (syndesmotic) and anterior cartilaginous parts of the sacroiliac joints. The ligamentous portion of the joint is well visualized at the axial slice compared with the coronal slice (arrows).

signal intensities on T1-weighted MR images with varying signal intensity on T1FS or gradient-echo sequences. ${ }^{35,36}$ They may be seen with and without concomitant BME corresponding to subchondral plate disruption and subchondral tissue infiltrates at biopsies. ${ }^{34}$

2. Sclerosis: subchondral low-intensity signal at the sacroiliac joint on all sequences (-Fig. 4).

3. Fatty conversion of bone marrow (esterification): subchondral hyperintense signal on T1, T2, and PD-weighted images, which is suppressed on FS sequences (-Fig. 4).

4. Bony bridges, ankyloses ( - Fig. 4): bony appositions, end stage of disease with union across the joint.

\section{MRI of the Spine}

\section{Rheumatoid Arthritis}

In RA patients, MRI of the spine is usually performed to assess the presence of inflammation and possible complications in the atlantoaxial, atlanto-occipital, and subaxial areas (synovitis, odontoid BME and erosions, $\mathrm{C} 1-\mathrm{C} 2$ subluxation or 

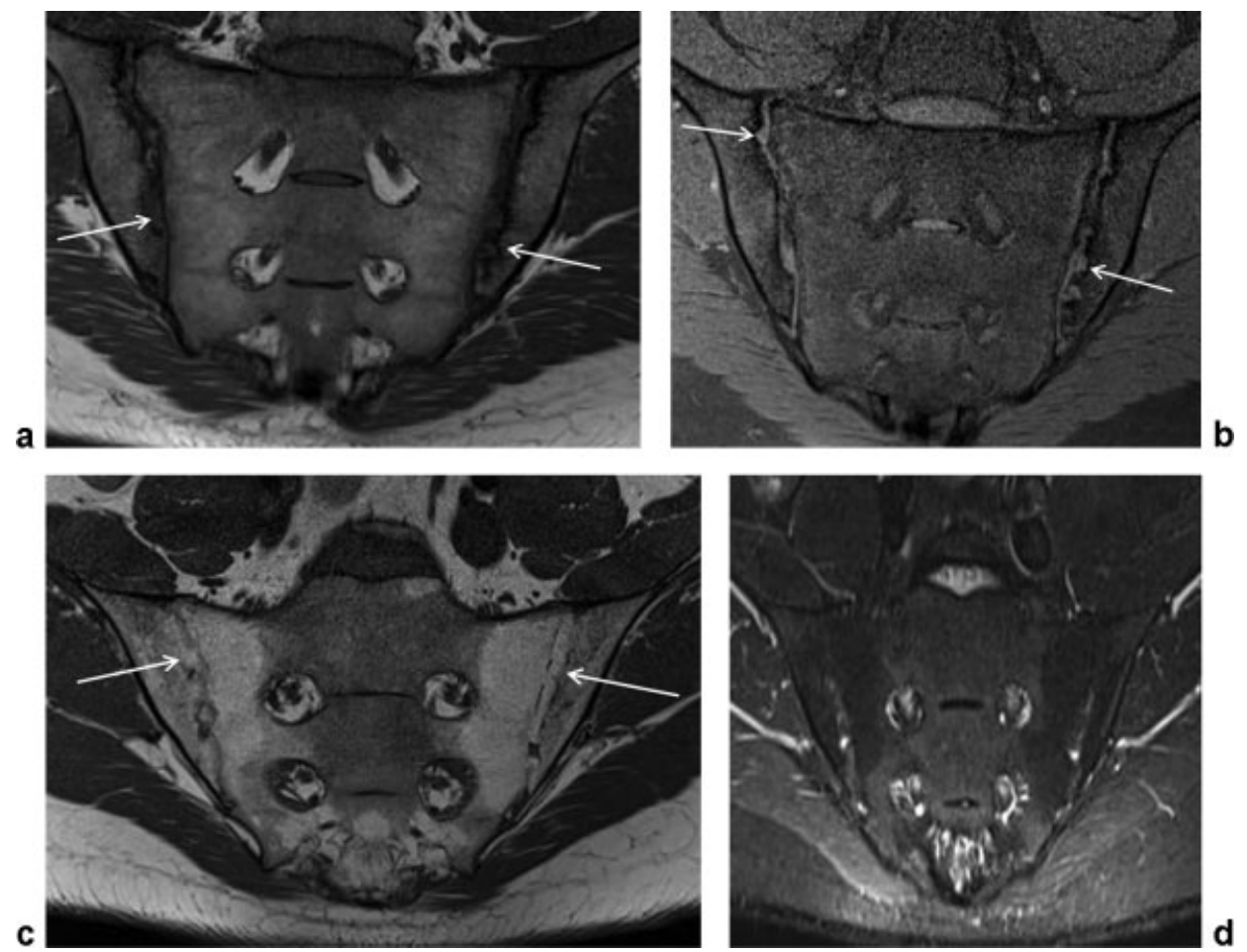

Fig. 4 Structural lesions of the sacroiliac joint in spondyloarthritis. Early changes: erosions on T1-weighted (a) and T1 fat-suppressed (b) images. Late changes: partial ankylosis and fatty infiltration of subchondral bone marrow on T1-weighted (c) and T2 turbo inversion recovery magnitude (d) images (arrows).

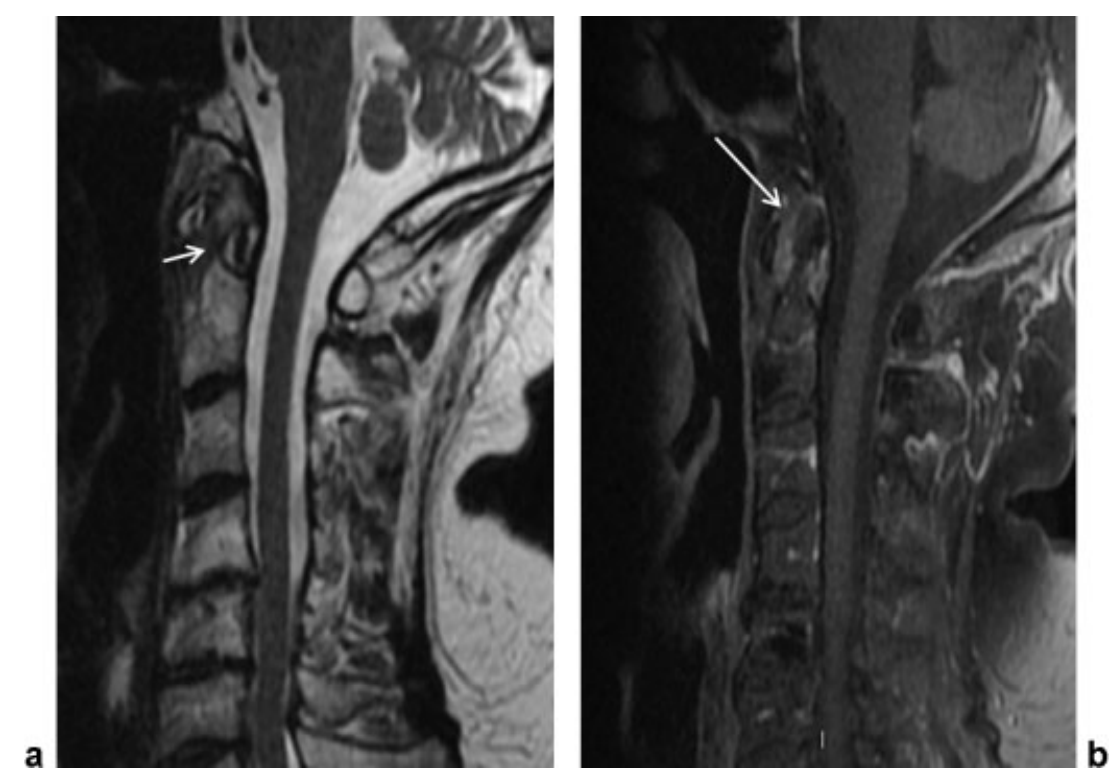

Fig. 5 Structural and active lesions in rheumatoid arthritis. Sagittal T1-weighted images (a) before and (b) after gadolinium administration of the cervical spine show erosions of the dens (short arrow) and enhancing synovium in the C1-C2 joint (synovitis) (long arrow).

Table 4 Types of typical MRI lesions of the sacroiliac joints according to ASAS ${ }^{8}$

\begin{tabular}{|l|l|}
\hline Active inflammatory lesions & Structural lesions \\
\hline 1. Bone marrow edema & 1. Subchondral sclerosis \\
\hline 2. Capsulitis & 2. Bone erosions \\
\hline 3. Synovitis & $\begin{array}{l}\text { 3. Periarticular fat } \\
\text { deposition }\end{array}$ \\
\hline 4. Enthesitis & 4. Bony bridges, ankyloses \\
\hline
\end{tabular}

Abbreviation: ASAS, Assessment of SpondyloArthritis Society. 

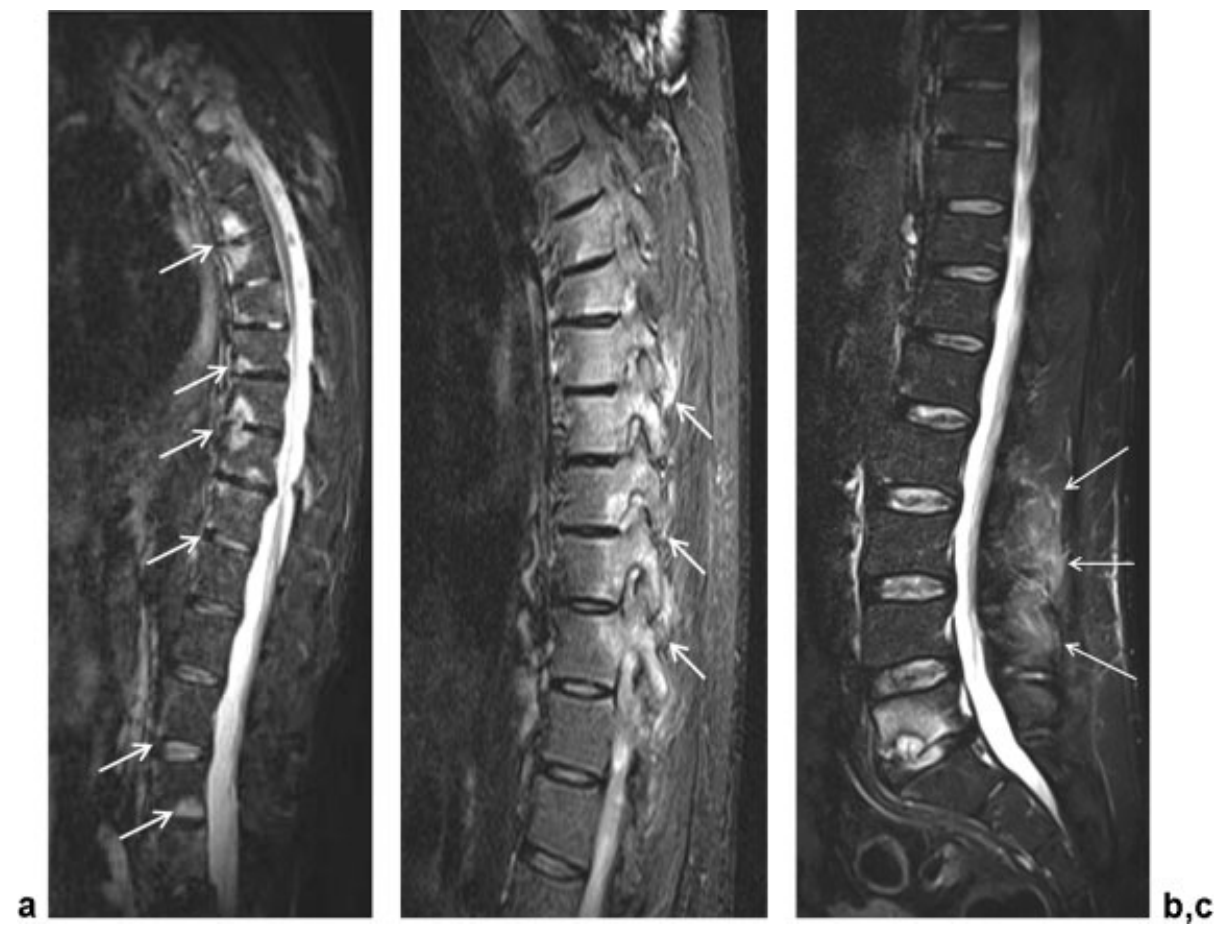

Fig. 6 Active inflammatory lesions of the spine in spondyloarthritis. Sagittal (a) short tau inversion recovery (STIR) image shows corner inflammatory lesions and active erosions (arrows) in the anterior, superior, and inferior aspect of multiple thoracic and lumbar spine vertebrae. (b) Sagittal STIR image shows inflammation of multiple costovertebral and apophyseal joints (arrows). (c) Sagittal STIR image shows inflammation of supraspinous and interspinous ligaments (arrows).

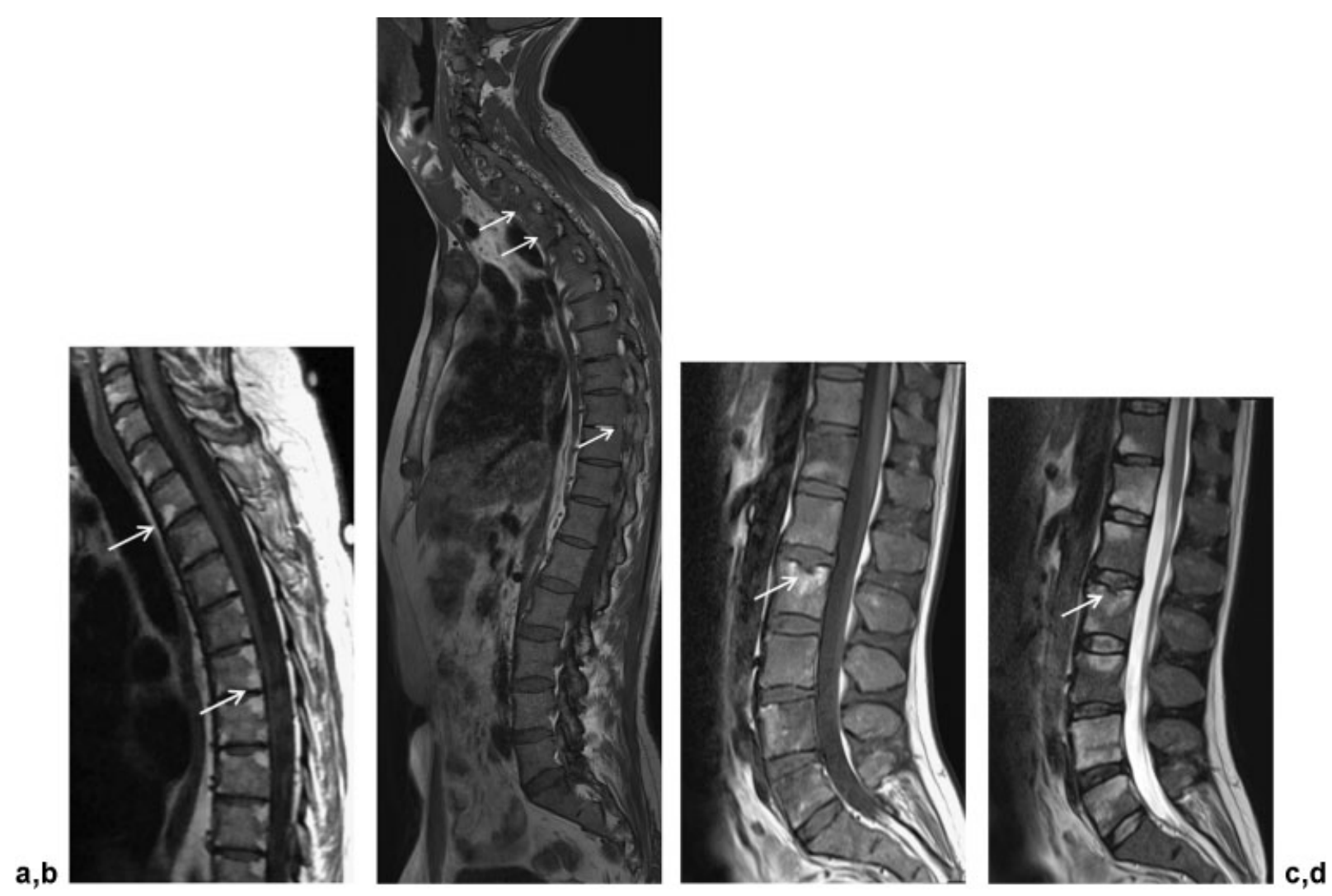

Fig. 7 Structural changes of the spine in spondyloarthritis (SpA). (a) Sagittal T1-weighted MR image shows fatty corner lesions in multiple vertebral bodies (arrows). (b) T1-weighted MR image shows ankylosis of multiple segments (arrows). (c) T1-weighted and (d) short tau inversion recovery MR images show vertebral plate erosion (arrow) as part of aseptic spondylodiscitis in SpA. There is a surrounding mixture of bone marrow edema and fatty infiltration, signs indicating active inflammation in addition to sequels of previous inflammation. 
basilar invagination, and/or subaxial spinal stenosis) ${ }^{29}$ (-Fig. 5).

\section{Spondyloarthritis}

Typical MR features of axial SpA include corner inflammatory lesions; aseptic noninfectious discitis with erosions of the end plates, zygo-apophyseal joint inflammation, costovertebral joint inflammation, inflammation of the posterior spinal elements, and ankylosis ${ }^{37}$ (-Figs. 6 and 7). Lesions of the lateral thoracic elements are very specific for the diagnosis of axial SpA. ${ }^{8}$

Juvenile Idiopathic Arthritis/ Juvenile Spondyloarthritis MRI of the cervical spine is usually performed to assess the activity of inflammation, including subclinical cases, and to diagnose complications in the atlantodental and atlantooccipital region, suspected on radiographs (-Fig. 8).

\section{MRI of Peripheral Joints}

In peripheral joints, thickening of the synovium, enhancement of the inflamed synovium, effusion, bone erosions, and BME can be demonstrated (-Figs. 9-15).

Synovitis can be assessed on T1FS sequences following contrast administration. The enhancement within the synovial membrane should be examined within no longer than 10 minutes from contrast administration. ${ }^{38}$ After this time, the contrast agent permeates into the synovial fluid. Fibrosis within the synovium results in low contrast enhancement. The same applies to hemosiderin occurring in pigmented villonodular synovitis (-Fig. 11).

BME in the course of the inflammation is seen as a hyperintense area on T2- and PD-weighted images, best visualized by T2 FS or STIR/TIRM sequences, hypointense on T1-weighted images with enhancement following contrast administration.
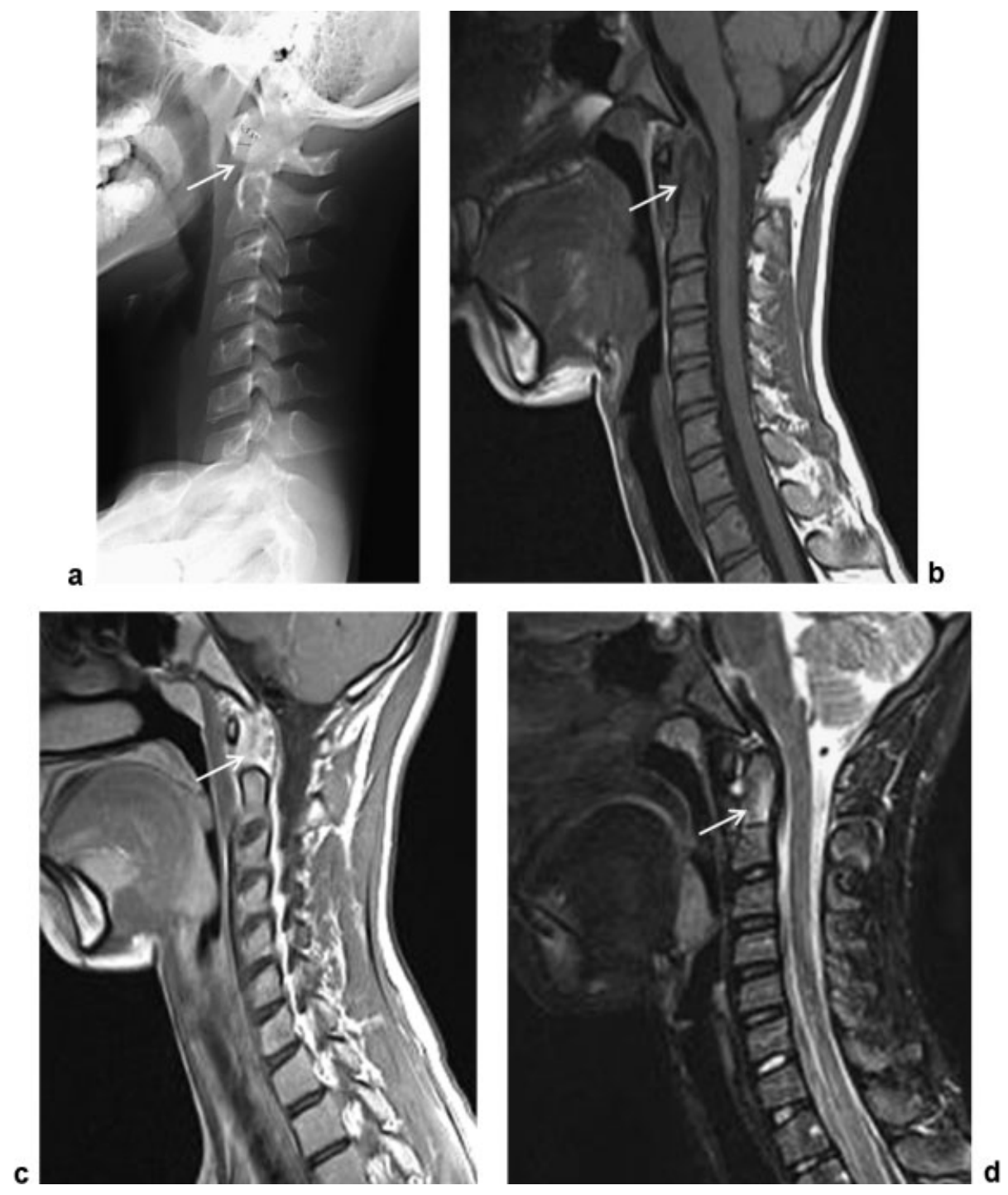

Fig. 8 Active inflammation in a 12-year-old boy with juvenile idiopathic arthritis. (a) Cervical spine radiograph shows C1-C2 subluxation (arrow). (b, c) Sagittal T1-weighted MR images before and after contrast enhancement show synovium enhancement at the C1-C2 joint (arrows). (d) Fat saturated T2-weighted MR image shows bone marrow edema in odontoid process (arrow). 

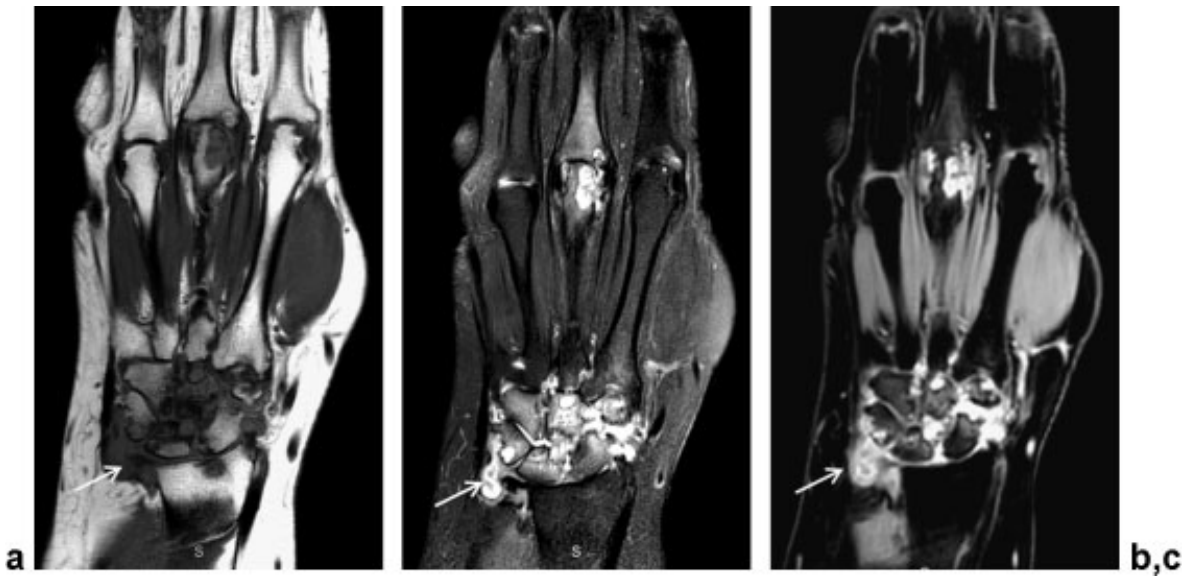

Fig. 9 Hand and wrist inflammation in rheumatoid arthritis. Coronal (a) T1-weighted, (b) fat- saturated T2-weighted, and (c) fat-saturated contrast-enhanced T1-weighted MR images show multiple bone erosions. Synovitis (arrows) is depicted mainly in the wrist and metacarpophalangeal III joint. Diffuse bone marrow edema (osteitis) is also clearly seen in the wrist bones and in the base of the third phalange.
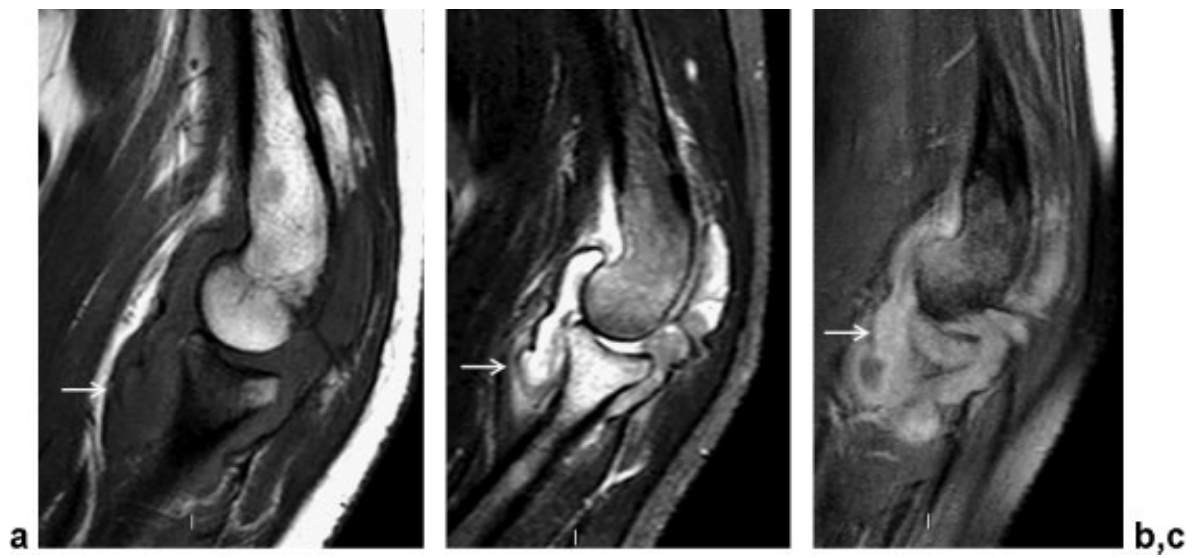

Fig. 10 Active inflammation of the elbow joint in a 16-year-old girl with juvenile idiopathic arthritis. Sagittal (a) T1-weighted, (b) T2 fatsuppressed, and (c) fat-saturated contrast-enhanced T1-weighted images show synovitis (arrows) in the elbow joint space.
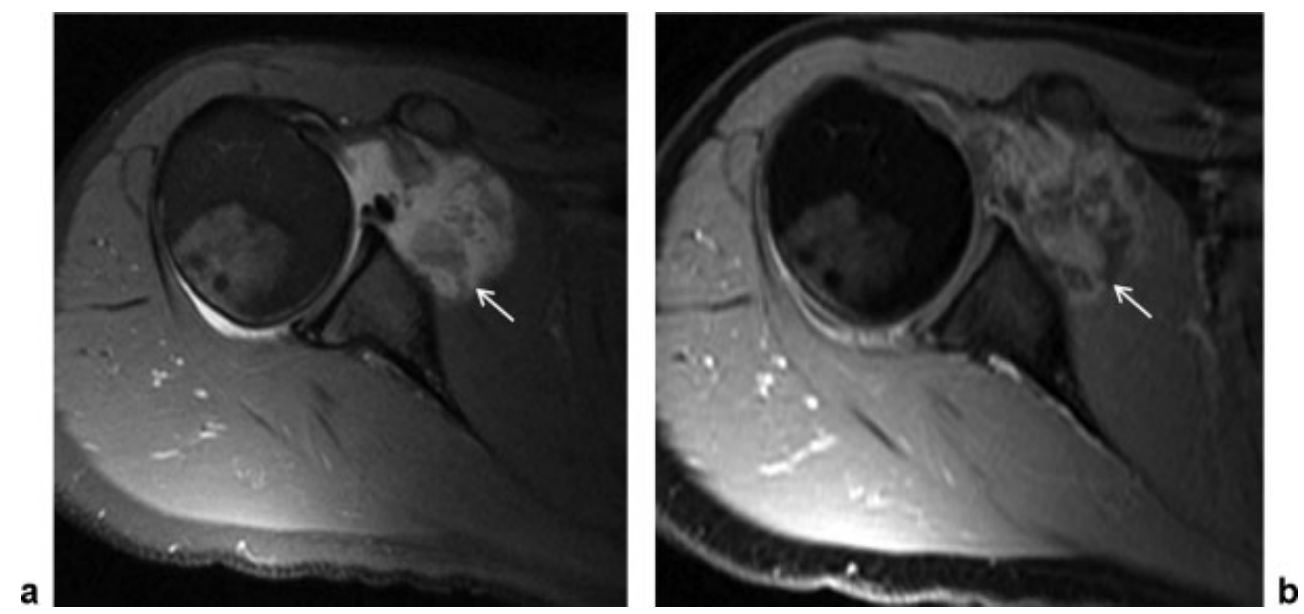

Fig. 11 Pigmented villonodular synovitis of the shoulder of a 34-year-old woman. Axial (a) fat-saturated T2-weighted and (b) fat-saturated contrast-enhanced T1-weighted show synovial proliferation with hypointense signal (arrows) due to hemosiderin deposition. 

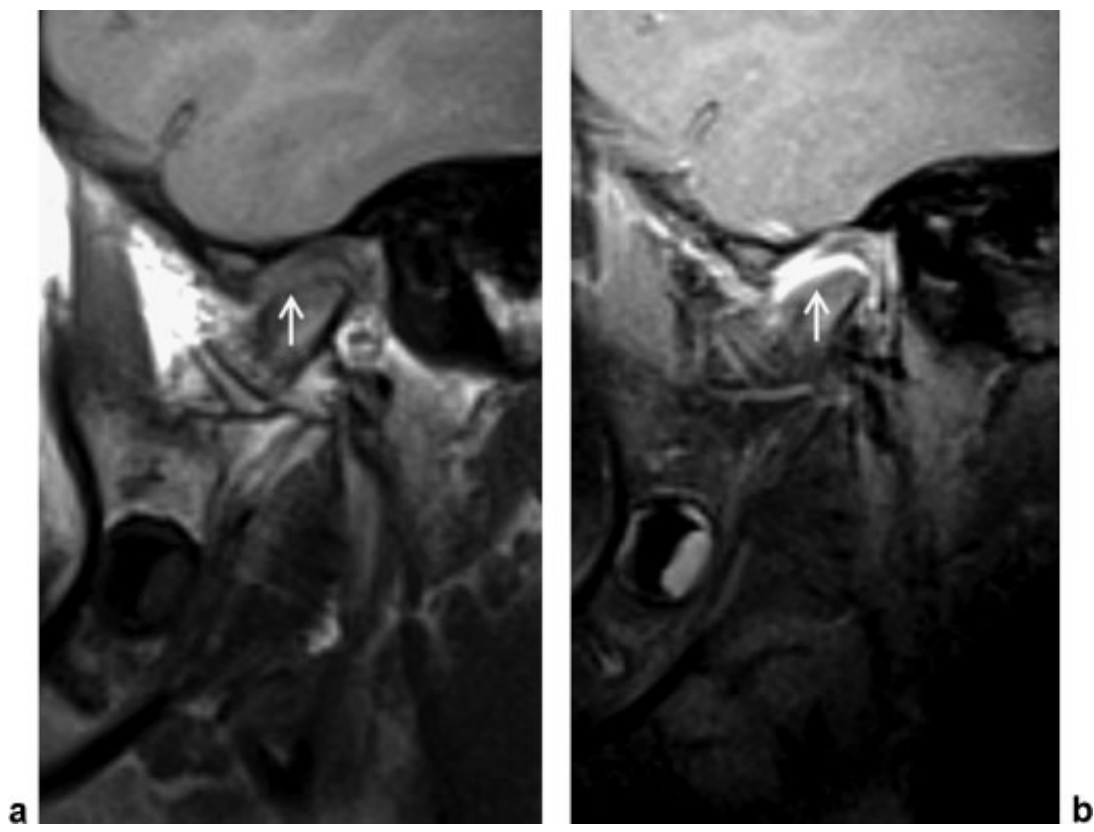

Fig. 12 Active inflammation of the temporomandibular joints. Sagittal T1-weighted images (a) before and (b) after contrast administration show synovitis (arrows) in the temporomandibular joint space.
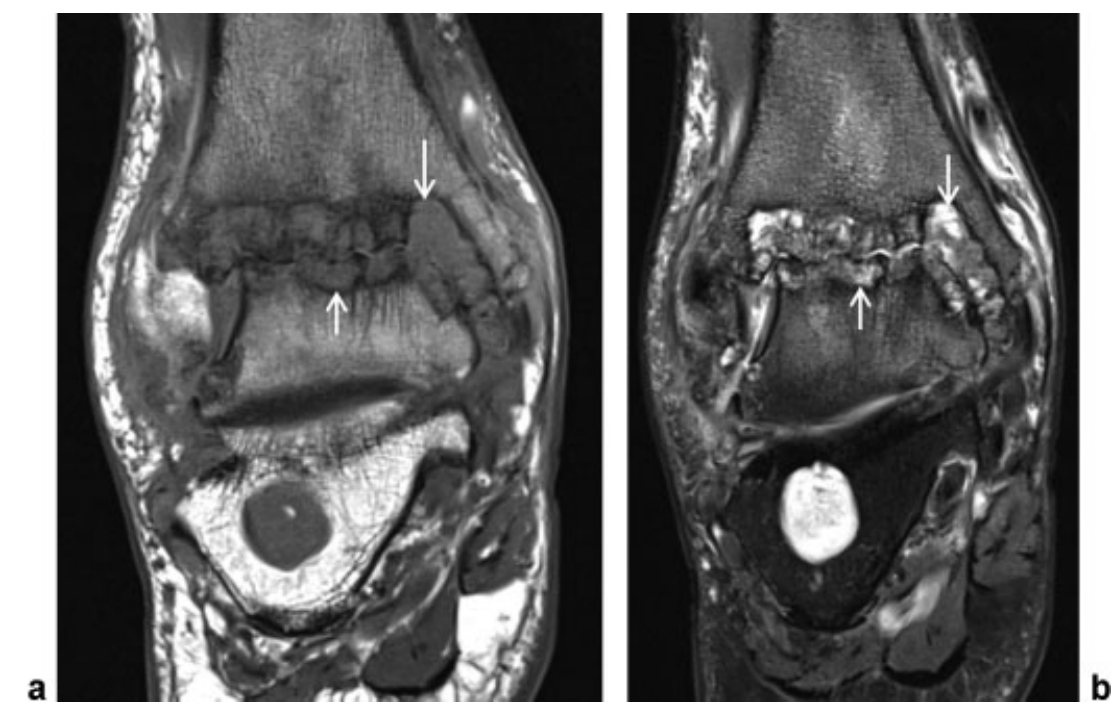

Fig. 13 Ankle arthritis in rheumatoid arthritis. Coronal (a) T1-weighted and (b) fat-suppressed T2-weighted MR images show extensive erosions (arrows) with fluid signal (exudate) of the tibiotalar joint; a benign cyst in the calcaneum.

Intraosseous cysts present as high signal intensity foci on T2-weighted images and low signal intensity on T1-weighted images, and they are better delineated compared with illdefined areas of BME.

Bone erosions are sharply marginated trabecular bone defects with disrupted cortical bone continuity, seen in at least two planes, with low signal intensity on T1-weighted images. ${ }^{39}$

Joint effusions are hyperintense on T2- and PD-weighted images, hypointense on T1-weighted images, and do not enhance immediately following contrast agent administration. ${ }^{31,32}$
In peripheral as well as in axial SpA, enthesitis may develop. MRI is highly sensitive for visualizing active enthesitis and depicts an abnormal signal in the fibrous and bony part of an enthesis, as well as peri-entheseal soft tissue involvement (synovium and fatty tissue). ${ }^{40,41}$ Extensive and diffuse patterns of BME are more closely related to inflammatory enthesitis. However, differentiation between the different causes of enthesitis (i.e., inflammatory, mechanical, metabolic, endocrine) is only feasible in the context of the available clinical information. Despite these limitations, MRI represents a significant advance for the early diagnosis of 

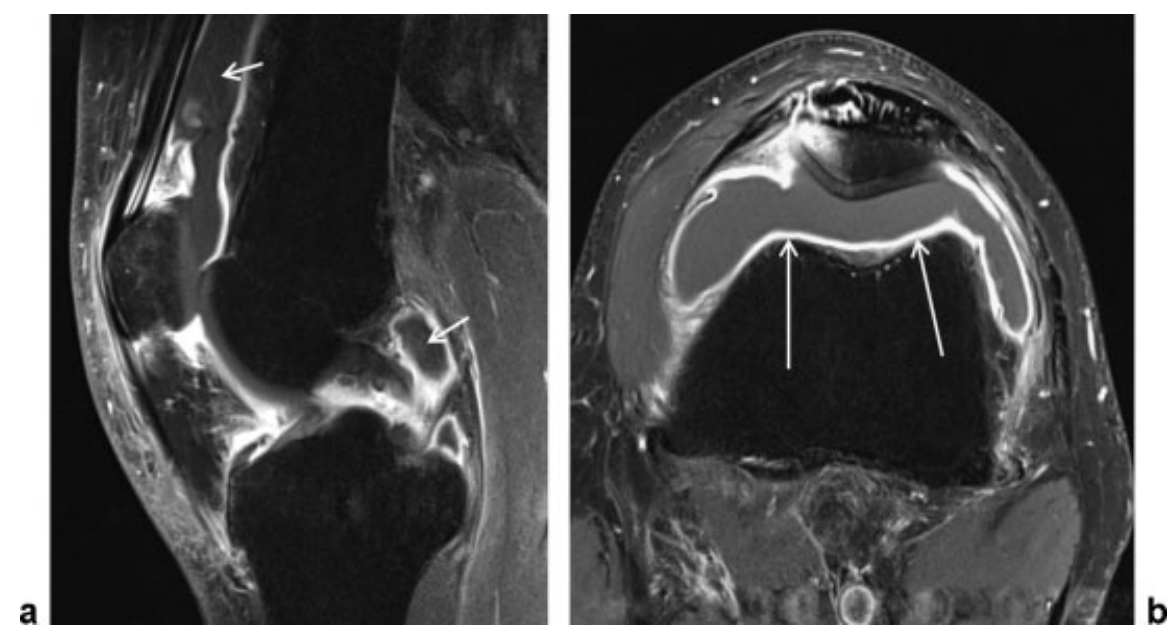

Fig. 14 Knee arthritis in psoriatic arthritis. Sagittal (a) and axial (b) fat-saturated contrast-enhanced T1-weighted MR images show joint effusion (arrows) and synovial enhancement (long arrows).

enthesitis-related arthropathies and for monitoring therapy that targets entheseal inflammation.

On MRI, an abnormal enthesis is hyperintense on T2 and PD-weighted images, best visualized by T2 FS or STIR/TIRM sequences, and is hypointense on T1-weighted images. The bony part of an enthesis may show BME. Both fibrous and bony parts show enhancement following contrast administration, as well as inflamed neighboring synovial and adipose tissues $^{40,41}$ (- Fig. 16). Enthesophytes can also be detected.
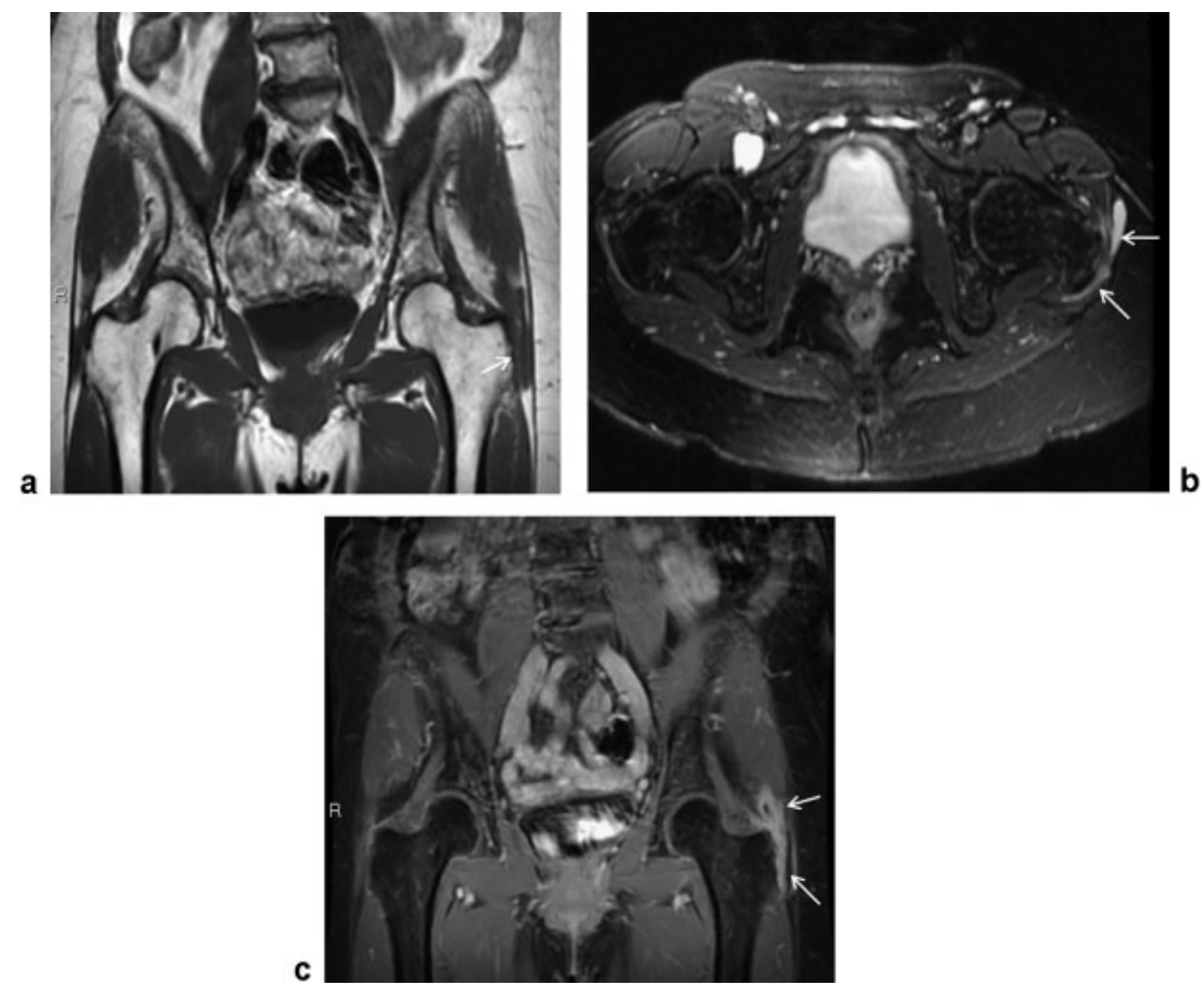

Fig. 15 Pelvic enthesitis. Coronal T1-weighted (a), axial fat-saturated T2-weighted (b), and coronal fat-saturated contrast-enhanced T1-weighted (c) images show enhancement of the enlarged gluteus medius bursa (arrows) and within its enthesis on the greater trochanter (arrows) in keeping with gluteus medius bursitis and enthesitis. 

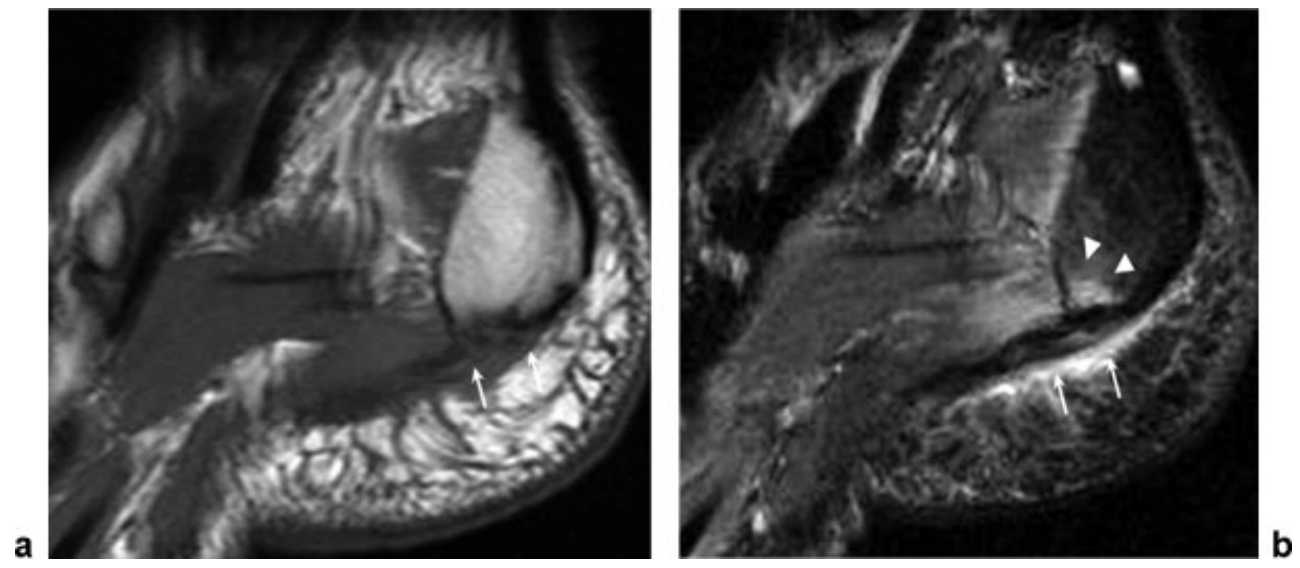

Fig. 16 Plantar fasciitis in spondyloarthritis. (a) Sagittal T1-weighted and (b) fat-suppressed T2-weighted images show thickening of the plantar fascia with surrounding soft tissue edema (arrows) and bone marrow edema in the calcaneal attachment (arrowheads) compatible with plantar fascia enthesitis.

\section{Assessment of MR Images}

MRI assessment is usually qualitative. However, several timeconsuming semiquantitative methods exist for RA, psoriatic arthritis, and axial SpA that are mostly used in research studies. $^{35,39,42-46}$
Dynamic contrast-enhanced MRI (DCE-MRI) allows for the assessment of the degree of enhancement of inflamed synovium, and it has been used for evaluating RA, osteoarthritis, psoriatic arthritis, and JIA. ${ }^{47-52}$

DCE-MRI consists of imaging of the same slices at intervals of several seconds during and after intravenous contrast

a
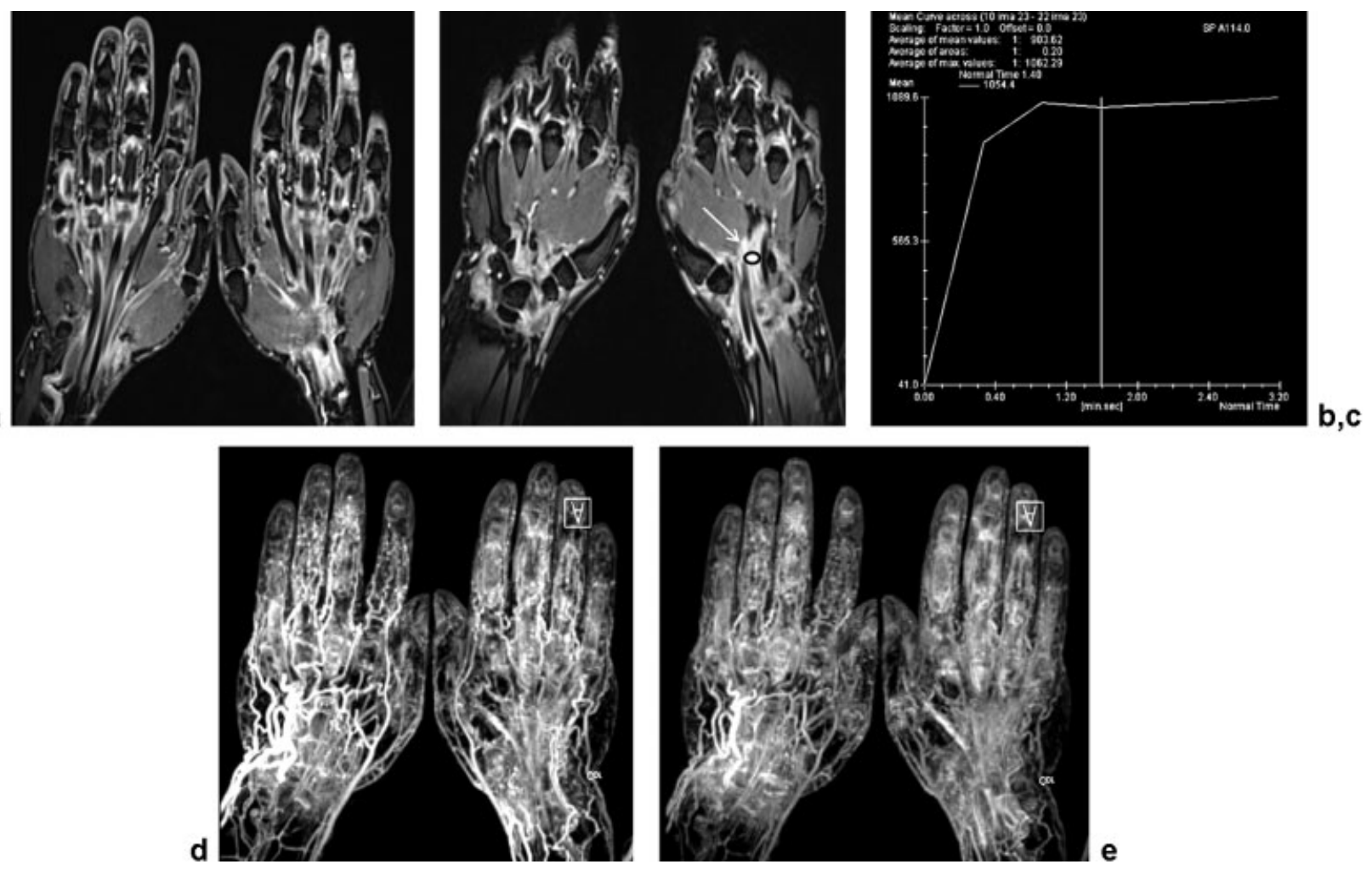

Fig. 17 Dynamic MR imaging in early inflammatory rheumatoid arthritis. (a) Coronal contrast-enhanced fat-suppressed volumetric interpolated breath-hold examination (VIBE) MR image shows marked synovitis of the flexor tendons, intercarpal, and metacarpophalangeal joints. (b) Drawing of region of interest (ROI) on a coronal VIBE MR image. (c) Signal intensity/time curve after gadolinium (corresponding to the represented ROI) representative of a high early enhancing rate pattern. (d) Maximum intensity projection of a three-dimensional (3D) digitally subtracted data set of the second VIBE acquisition after contrast (20 seconds after contrast administration) indicates early increased vascularity due to synovitis. (e) Maximum intensity projection of a 3D digitally subtracted data set of the seventh VIBE acquisition after contrast (70 seconds after contrast administration), indicative of late persistent increased vascularity due to synovitis. 
administration for a period of 2 to 5 minutes (-Fig. 17). Absolute and relative enhancement of the synovium can be obtained from the analysis reflecting synovial perfusion and permeability of capillary vessels within the inflamed tissue. This is correlated with the degree of synovial vascularization, which may be useful in monitoring treatment, ${ }^{37}$ but the reproducibility in multicenter studies still needs to be determined.

\section{Conclusion}

The Arthritis Subcommittee of the ESSR recommends MRI as an accurate and objective modality for the diagnosis and follow-up of rheumatologic conditions. It is the method of choice for the assessment of early involvement of the spine and sacroiliac joints, and for monitoring axial SpA activity. Contrast-enhanced MRI can be used to evaluate the inflammatory activity of synovium as well as bone marrow.

Currently MRI is the most promising method to evaluate objectively the severity of inflammation, to diagnose subclinical axial and peripheral inflammation, and to confirm remission. Finally MRI holds promise in deepening our knowledge about the etiopathogenesis of rheumatoid diseases.

\section{References}

1 Schueller-Weidekamm C, Mascarenhas VV, Sudol-Szopinska I, et al. Imaging and interpretation of axial spondylarthritis: the radiologist's perspective-consensus of the Arthritis Subcommittee of the ESSR. Semin Musculoskelet Radiol 2014;18(3):265-279

2 Rudwaleit M, van der Heijde D, Landewé R, et al. The development of Assessment of SpondyloArthritis international Society classification criteria for axial spondyloarthritis (part II): validation and final selection. Ann Rheum Dis 2009;68(6):777-783

3 Rudwaleit M, van der Heijde D, Landewé R, et al. The Assessment of SpondyloArthritis International Society classification criteria for peripheral spondyloarthritis and for spondyloarthritis in general. Ann Rheum Dis 2011;70(1):25-31

4 van den Berg R, van der Heijde DMFM. How should we diagnose spondyloarthritis according to the ASAS classification criteria: a guide for practicing physicians. Pol Arch Med Wewn 2010; 120(11):452-457

5 Mandl P, Navarro-Compán V, Terslev L, et al; European League Against Rheumatism (EULAR). EULAR recommendations for the use of imaging in the diagnosis and management of spondyloarthritis in clinical practice. Ann Rheum Dis 2015;74(7):1327-1339

6 Aletaha D, Neogi T, Silman AJ, et al. 2010 rheumatoid arthritis classification criteria: an American College of Rheumatology/ European League Against Rheumatism collaborative initiative. Arthritis Rheum 2010;62(9):2569-2581

7 Colebatch AN, Edwards CJ, Østergaard M, et al. EULAR recommendations for the use of imaging of the joints in the clinical management of rheumatoid arthritis. Ann Rheum Dis 2013; 72(6):804-814

8 Sieper J, Rudwaleit M, Baraliakos X, et al. The Assessment of SpondyloArthritis international Society (ASAS) handbook: a guide to assess spondyloarthritis. Ann Rheum Dis 2009;68(2, Suppl 2): ii1-ii44

9 Weber U, Zubler V, Zhao Z, et al. Does spinal MRI add incremental diagnostic value to MRI of the sacroiliac joints alone in patients with non-radiographic axial spondyloarthritis? Ann Rheum Dis 2014
10 Østergaard M. Clarification of the role of ultrasonography, magnetic resonance imaging and conventional radiography in the ACR/ EULAR 2010 rheumatoid arthritis classification criteria: comment to the article by Aletaha et al. Ann Rheum Dis 2010

11 Aletaha D, Hawker G, Neogi T, Silman A. Re: Clarification of the role of ultrasonography, magnetic resonance imaging and conventional radiography in the ACR/EULAR 2010 rheumatoid arthritis classification criteria: comment to the article by Aletaha et al. Ann Rheum Dis 2011

12 Stomp W, Krabben A, van der Heijde D, et al. Are rheumatoid arthritis patients discernible from other early arthritis patients using $1.5 \mathrm{~T}$ extremity magnetic resonance imaging? A large crosssectional study. J Rheumatol 2014;41(8):1630-1637

13 van Steenbergen HW, van Nies JA, Huizinga TW, Bloem JL, Reijnierse M, van der Helm-van Mil AH. Characterising arthralgia in the preclinical phase of rheumatoid arthritis using MRI. Ann Rheum Dis 2015;74(6):1225-1232

14 Hetland ML, Stengaard-Pedersen K, Junker P, et al; CIMESTRA study group. Radiographic progression and remission rates in early rheumatoid arthritis-MRI bone oedema and anti-CCP predicted radiographic progression in the 5-year extension of the double-blind randomised CIMESTRA trial. Ann Rheum Dis 2010; 69(10):1789-1795

15 Krabben A, Stomp W, van Nies JA, et al. MRI-detected subclinical joint inflammation is associated with radiographic progression. Ann Rheum Dis 2014;73(11):2034-2037

16 Müller LS, Avenarius D, Damasio B, et al. The paediatric wrist revisited: redefining MR findings in healthy children. Ann Rheum Dis 2011;70(4):605-610

17 Doria AS, Babyn PS, Feldman B. A critical appraisal of radiographic scoring systems for assessment of juvenile idiopathic arthritis. Pediatr Radiol 2006;36(8):759-772

18 Hemke R, Maas M, van Veenendaal M, et al. Contrast-enhanced MRI compared with the physical examination in the evaluation of disease activity in juvenile idiopathic arthritis. Eur Radiol 2014; 24(2):327-334

19 Hemke R, van Veenendaal M, Kuijpers TW, van Rossum MA, Maas M Increasing feasibility and patient comfort of MRI in children with juvenile idiopathic arthritis. Pediatr Radiol 2012;42(4):440-448

20 Hemke R, van Rossum MA, van Veenendaal M, et al. Reliability and responsiveness of the Juvenile Arthritis MRI Scoring (JAMRIS) system for the knee. Eur Radiol 2013;23(4):1075-1083

21 Hemke R, van Veenendaal M, van den Berg JM, et al. One-year followup study on clinical findings and changes in magnetic resonance imaging-based disease activity scores in juvenile idiopathic arthritis. J Rheumatol 2014;41(1):119-127

22 Nusman CM, Ording Muller LS, Hemke R, et al. Current status of efforts on standardizing magnetic resonance imaging of juvenile idiopathic arthritis: report from the OMERACT MRI in JIA Working Group and Health-e-Child. J Rheumatol 2015; May 15 (Epub ahead of print)

23 Nistala K, Babar J, Johnson K, et al. Clinical assessment and core outcome variables are poor predictors of hip arthritis diagnosed by MRI in juvenile idiopathic arthritis. Rheumatology (Oxford) 2007;46(4):699-702

24 Damasio MB, de Horatio LT, Boavida P, et al. Imaging in juvenile idiopathic arthritis (JIA): an update with particular emphasis on MRI. Acta Radiol 2013;54(9):1015-1023

25 Sheybani EF, Khanna G, White AJ, Demertzis JL. Imaging of juvenile idiopathic arthritis: a multimodality approach. Radiographics 2013;33(5):1253-1273

26 Bollow M, Biedermann T, Kannenberg J, et al. Use of dynamic magnetic resonance imaging to detect sacroiliitis in HLA-B27 positive and negative children with juvenile arthritides. J Rheumatol 1998;25(3):556-564

27 Tse SM, Laxer RM. New advances in juvenile spondyloarthritis. Nat Rev Rheumatol 2012;8(5):269-279 
28 Stomp W, Krabben A, van der Heijde D, et al. Aiming for a simpler early arthritis MRI protocol: can Gd contrast administration be eliminated? Eur Radiol 2015;25(5):1520-1527

29 Younes M, Belghali S, Kriâa S, et al. Compared imaging of the rheumatoid cervical spine: prevalence study and associated factors. Joint Bone Spine 2009;76(4):361-368

30 Giraudo C, Magnaldi S, Weber M, et al. Optimizing the MRI protocol of the sacroiliac joints in spondyloarthritis: which para-axial sequence should be used? Eur Radiol 2015

31 Hemke R, Kuijpers TW, van den Berg JM, et al. The diagnostic accuracy of unenhanced MRI in the assessment of joint abnormalities in juvenile idiopathic arthritis. Eur Radiol 2013;23(7): 1998-2004

32 Østergaard M, Conaghan PG, O'Connor P, et al. Reducing invasiveness, duration, and cost of magnetic resonance imaging in rheumatoid arthritis by omitting intravenous contrast injection-does it change the assessment of inflammatory and destructive joint changes by the OMERACT RAMRIS? J Rheumatol 2009;36(8): 1806-1810

33 Puhakka KB, Melsen F, Jurik AG, Boel LW, Vesterby A, Egund N. MR imaging of the normal sacroiliac joint with correlation to histology. Skeletal Radiol 2004;33(1):15-28

34 Gong Y, Zheng N, Chen SB, et al. Ten years' experience with needle biopsy in the early diagnosis of sacroiliitis. Arthritis Rheum 2012; 64(5):1399-1406

35 Madsen KB, Jurik AG. MRI grading system for active and chronic spondyloarthritis changes in the sacroiliac joint. Arthritis Care Res 2010;62(1):11-18

36 Wick MC, Grundtman C, Weiss RJ, et al. The time-averaged inflammatory disease activity estimates the progression of erosions in MRI of the sacroiliac joints in ankylosing spondylitis. Clin Rheumatol 2012;31(7):1117-1121

37 Lambert RGW, Pedersen SJ, Maksymowych WP, Chiowchanwisawakit P, Østergaard M. Active inflammatory lesions detected by magnetic resonance Imaging in the spine of patients with spondyloarthritis-definitions, assessment system, and reference image set. J Rheumatol 2009;36(Suppl 84):3-17

38 Østergaard M, Klarlund M. Importance of timing of post-contrast MRI in rheumatoid arthritis: what happens during the first 60 minutes after IV gadolinium-DTPA? Ann Rheum Dis 2001;60(11): 1050-1054

39 Østergaard M, Peterfy C, Conaghan P, et al. OMERACT Rheumatoid Arthritis Magnetic Resonance Imaging Studies. Core set of MRI acquisitions, joint pathology definitions, and the OMERACT RAMRI scoring system. J Rheumatol 2003;30(6):1385-1386

40 Eshed I, Bollow M, McGonagle DG, et al. MRI of enthesitis of the appendicular skeleton in spondyloarthritis. Ann Rheum Dis 2007; 66(12):1553-1559
41 Jans L, van Langenhove C, Van Praet L, et al. Diagnostic value of pelvic enthesitis on MRI of the sacroiliac joints in spondyloarthritis. Eur Radiol 2014;24(4):866-871

42 Østergaard M, Edmonds J, McQueen F, et al. An introduction to the EULAR-OMERACT rheumatoid arthritis MRI reference image atlas. Ann Rheum Dis 2005;64(Suppl 1):i3-i7

43 Østergaard M, McQueen F, Wiell C, et al. The OMERACT psoriatic arthritis magnetic resonance imaging scoring system (PsAMRIS): definitions of key pathologies, suggested MRI sequences, and preliminary scoring system for PsA Hands. J Rheumatol 2009; 36(8):1816-1824

44 Maksymowych WP, Inman RD, Salonen D, et al. Spondyloarthritis Research Consortium of Canada magnetic resonance imaging index for assessment of spinal inflammation in ankylosing spondylitis. Arthritis Rheum 2005;53(4):502-509

45 Haibel $\mathrm{H}$, Rudwaleit M, Brandt $\mathrm{HC}$, et al. Adalimumab reduces spinal symptoms in active ankylosing spondylitis: clinical and magnetic resonance imaging results of a fifty-two-week openlabel trial. Arthritis Rheum 2006;54(2):678-681

46 Madsen KB, Jurik AG. MRI grading method for active and chronic spinal changes in spondyloarthritis. Clin Radiol 2010;65(1):6-14

47 Jans L, De Coninck T, Wittoek R, et al. 3 T DCE-MRI assessment of synovitis of the interphalangeal joints in patients with erosive osteoarthritis for treatment response monitoring. Skeletal Radiol 2013;42(2):255-260

48 Østergaard M, Poggenborg RP, Axelsen MB, Pedersen SJ. Magnetic resonance imaging in spondyloarthritis-how to quantify findings and measure response. Best Pract Res Clin Rheumatol 2010;24(5): 637-657

49 Axelsen MB, Stoltenberg M, Poggenborg RP, et al. Dynamic gadolinium-enhanced magnetic resonance imaging allows accurate assessment of the synovial inflammatory activity in rheumatoid arthritis knee joints: a comparison with synovial histology. Scand J Rheumatol 2012;41(2):89-94

50 Poggenborg RP, Wiell C, Bøyesen P, et al. No overall damage progression despite persistent inflammation in adalimumabtreated psoriatic arthritis patients: results from an investigatorinitiated 48-week comparative magnetic resonance imaging, computed tomography and radiography trial. Rheumatology (Oxford) 2014;53(4):746-756

51 van der Leij C, van de Sande MG, Lavini C, Tak PP, Maas M. Rheumatoid synovial inflammation: pixel-by-pixel dynamic contrast-enhanced MR imaging time-intensity curve shape analysisa feasibility study. Radiology 2009;253(1):234-240

52 Hemke R, Lavini C, Nusman CM, et al. Pixel-by-pixel analysis of DCE-MRI curve shape patterns in knees of active and inactive juvenile idiopathic arthritis patients. Eur Radiol 2014;24(7): 1686-1693 